\title{
The Use of Augmented Reality Pop-Up Book to Increase Motivation in English Language Learning For National Primary School
}

\author{
Nor Nashirah Nor Mahadzir ${ }^{1}$, Li Funn Phung ${ }^{2}$ \\ ${ }^{1,2}$ (Centre for Instructional Technology and Multimedia, Universiti Sains Malaysia, Malaysia)
}

\begin{abstract}
This research study describes the use of Augmented Reality (AR) as an emerging form of experience in which the real world is enhanced by computer-generated content. AR pop-up books for instance will help students bridge the gap between the digital and physical world. Students are able to use the AR pop-up book as the primary interface, changing perspective or direction by moving the book through their webcam where a marker detection which is a two-dimensional patterns to carry information that are attached to the book page. AR technology is adopted in this research study because it has the potential to motivate and support students in English language learning. In learning a second language, research has established that it is utmost important that students receive maximum support in terms of supportive and conducive learning environment. The AR pop-up book is developed using ZooBurst tool and the design is incorporated with a problem solving approach which is Keller's ARCS model: Attention, Relevance, Confidence, and Satisfaction. The development process is enhanced using Keller's ARCS model of motivational design. The result of the study is obtained from observations of Year One primary school students using the AR pop-up book and followed by semi-structured interview.
\end{abstract}

Keywords - ARCS model, ARCS model of motivational design, Augmented Reality pop-up book, English language learning, Motivation.

\section{INTRODUCTION}

The focus of interest in this empirical study is in the nature of promoting the augmented reality (AR) pop-up book to increase motivation in English language learning among Malaysian primary school students. English is taught as a second language of Standard British English in Malaysian primary school in Year One (seven years-old), right through Year Six (12 years-old). English is taken into consideration because of the fact that today knowledge comes to us in English language. English language encompasses most knowledge acquired processes. In addition, the concern for low English language literacy among Malaysian students is regarded. The commitment to address the low literacy has been highly regarded by the Malaysian government [1]. Motivation in English language learning among Malaysian primary school students is seen to be the main factor in the English language literary issue.

Legault, Green-Demers, and Pelletier, [2] reported one of the most prominent academic problems plaguing today teenage youth is a lack of motivation toward academic activities. This is mainly because of the instructional strategies that do not meet the needs of the learners. There is a lack of creative use of technology and active participation of students in the current primary school where English language learning is concerned, in addition to this, there are many Malaysian students who have problems in learning and communicating in English in schools [3]. Students need more meaningful interactions such as the use of augmented reality (AR) in classroom environment rather than the traditional method itself. Physical English book usually provide students with non-immersive experience with lack of motivation elements such as attention, confidence, and even satisfaction.

Augmented reality (AR) allows students to see the real world and have total immersion experience. At first instant, students may have encountered web applications which enable them for view quick response (QR) codes through their webcam [4]. QR codes or also known as marker which is a digital information that can be attached to images either on cards, papers, or other surfaces. When a marker is held in front of a webcam, students who are using the AR applications through computer can view digital content superimposed on the marker in their hands [4]. In addition, when students move or rotate the marker, the digital content will also moves or rotates together. Collaboration between the participants is achieved through the use of a tangible AR interfaces that use marker cards as well as an immersive AR environment which is based on software user interfaces (UIs) and hardware devices [5].

Furthermore, the English language learning lessons embedded in the augmented reality (AR) pop-up book are used where the theoretical framework is guided by Keller's ARCS model. The acronym ARCS is derived from four categories of motivational factors (Attention, Relevance, Confidence, and Satisfaction) that 
are based on an aggregation of motivational concepts and theories according to their shared and discriminative attributes [6]. The AR pop-up book is developed using the ZooBurst application tool through the step by step of ARCS motivational design process. The outline of this research study is given in Appendix 1.

Wei and Elias, [3] in their study reported that, teachers, schools, and the Ministry of Education find ways to increase interest in English language learning among learners and become intrinsically motivated to learn the language. Thus, the objectives of this research were to determine the relationship between augmented reality (AR) pop-up book and motivation among primary school students and to investigate the use of AR popup book towards English language learning.

The rest of the paper is structured as follows: Literature review has been discussed in section II, methodology is presented in section III, section IV describe complete application of augmented reality (AR) pop-up book, section V elaborated the findings, section VI presents discussion, and the paper is concluded in section VII.

\section{ZooBurst Tool for Augmented Reality (AR) Application}

\section{LITERATURE REVIEW}

ZooBurst is an educational digital storytelling tool that is designed to let anyone easily create their own augmented reality $3 \mathrm{D}$ pop-up books. ZooBurst can be experienced using a web browser running the Adobe Flash plug-in and a webcam. "The on-screen book is entirely interactive, allowing readers to change the page, click on characters to see dialogue, or tilt the paper in any direction to view the story from different angle" [4]. The interactivity in ZooBurst application gives students an opportunity for total immersion. The immersive in learning will increase motivation as well as allow students to improve performance

\section{Augmented Reality Technology in Education}

"The use of augmented reality (AR) in formal education could prove a key component in future learning environments that are rich populated with a blend of hardware and software applications" [7]. Similar to this, in the development of AR pop-up book in English language learning, it allows the digital content to be overlaid and mixed into student's perception of the real world.

In addition, Yuen, Yaoyuneyong, and Johnson, [4] describe in their research study that augmented reality (AR) technology has great potential to offer learners with 3D presentations and interactive experiences that are more appealing than digital native learning. The exciting presentations and experiences in AR technology will increase motivation in English language learning such as in ZooBurst. Students are able to interact with the book using simple gestures such as simply waving hand in front of the book to turn its pages. Also, Yuen, Yaoyuneyong, and Johnson, [4] have reviewed an example of AR book entitled "The Future is Wild: The Living Book" which is able to increase motivation in learning by encouraging students to build a connection to a book. The book was developed by Meatio, a company in Germany and launched at the Frankfurt Book Fair in 2011.

Further, learning with realistic audio-visual contents in AR technology will motivate learners by providing a better learning environment especially for learners in primary school, level 1 where learning with text itself is difficult. Related to this, according to Lee, Choi, and Park, [8] in their research study on e-learning system using AR technology, "the proposed e-learning system augments the audio-visual contents as the students interact with the objects in the text book". The used of audio-visual contents are proven to improve learning as the authors tested their proposed e-learning system with real elementary education courses, and they obtained successful result [8].

Augmented reality technology in education is a key element of future learning environments. It is also a promising educational tool that helps to enhance learning through motivation.

\section{English Language Learning in Primary School}

One of the important elements in learning is the student's motivation to learn English language from the beginning of formal education. "The motivation to learn English language among Malaysia students is vital in their process of learning" [3]. Performance will improve if students are motivated to learn.

According to Che Musa, Lie, and Azman, [1], "the study maintains that, apart from the linguistics obstacles, the social surroundings such as unenthusiastic attitude, lack of interest towards learning the language and the environment that do not encourage learners to use the language have worsened the effort of acquiring the language". Giving the exciting way of learning using interactive technology will make it possible to enhance student's interest to learn English.

Moreover, Zubairi and Sarudin, [9] stated that Puhafl, Christian, and Rhodes reviewed that "successful foreign language programmes shared several common features including (a) an early start for students to learn languages" and "... (g) creative use of technology". Therefore, primary school will be the best platform to enhance the development of English language learning skills by integrating interactive technology in learning so 
that the lessons are meaningful to learners. Knowing English language has become an added advantage and also an economic commodity.

\section{Keller's ARCS Model of Motivation}

Educators know the challenge of stimulating and sustaining learner motivation and the difficulty to find suitable methods for motivating learner [10]. Thus, Keller, [10] suggested one approach to meet this challenge which is the ARCS model of motivation where it provides systematic guidance to design motivational augmented reality (AR) pop-up book in English language learning. The framework of motivational augmented reality (AR) pop-up book in English language learning is given in Appendix 2.

Motivation in English language learning is vital because of the low English literacy among students in Malaysia and this is supported by Keller, [11] where "motivation to learn is promoted when a learner's curiosity is aroused due to a perceived gap in current knowledge".

To create an effective, efficient and attractive AR pop-up book, all the four categories of motivation (Attention, Relevance, Confidence, and Satisfaction) are necessary and require deep understanding [12]. In addition to the four categories of motivation, Keller, [10] provided the component parts, or subcategories that represent specific aspects of motivation. These component parts are essential in the development of augmented reality (AR) pop-up book for a learner to be fully motivated in English language learning.

The first step in motivation acquiring the Attention of the learner during the learning period and ensuring its continuity [12]. Relevance comes next where the content of the augmented reality (AR) pop-up book shouldn't be difficult to learner, the curiosity of whom is stimulated, to preserve interest and curiosities [12]. In addition to the next two categories of the ARCS model, Sali, [12] stated that "Confidence is where learners develop positive expectation in order to perform a high degree of success" and "Satisfaction is the result that learner get" from the English language learning with AR pop-up book.

\section{METHODOLOGY}

In this research study, two stages of data collections had been carried out. Observation had been carried out to observe the motivation level that the participants shown during the lesson. In addition, a semi-structured interview had been carried out to confirm the results derived from the observation. This process was recorded with permission. Thus, these two methods will then triangulate this research study.

\section{Participants}

Five participants from northern region in Malaysia were selected based on convenience sampling method. They were all aged seven and were in primary school. This sample group included one Indian male, one Malay male, and three Malay females.

Instruments

There were two instruments used in this research study. The first instrument which is given in Appendix 3 was the observation checklist adapted from Keller [13]. This instrument denotes not observed (1), more emphasis recommended (2), and accomplished very well (3). The right best number that represents the participants respond is circled throughout the observation by the researcher.

The second instrument was semi-structured interview as shown in Appendix 4. It has been derived from Keller's ARCS model of motivation [10]. The questions have been manipulated according to standard level of Year One students. The interview questions are provided in both English and Malay language.

\section{Data Collection}

In this research study, data was collected in the forms of observations and semi-structured interviews. Convenience sampling method was used to sample the sample group for both observations and interview sessions. Data were collected through:

Observations. Observations were conducted in a school library by the researcher during recess time and extend to the next one hour of lesson. The observation was done with one participant at a time and it took ten minutes for each participant to complete the English language learning using AR pop-up book. Participant briefing was held at the beginning of the learning. The researcher measured the motivation level of each participant by using the observation checklist In addition, video recording was done throughout the learning for further coding and transcribing processes.

Semi-structured Interviews. Interview sessions were conducted right after the observation session with one participant at a time. The setting remained the same. The interview session took approximately seven to ten minutes for each participant. A set of similar questions were asked accordingly. All the participants were interviewed in Malay language as requested by the primary school. Also, video recording was done for further coding and transcribing processes to repeat on what they said due to the nature of qualitative methodology. 
Data Analysis

Statistical Package for Social Science (SPSS) was used to measure the mean resulted from the observations. It was descriptive coding. Next, data from the interviews were analyzed using content analysis procedures. After the transcript process was done based on the interviews other data were intensively read and carefully coded to cross-examine possible underlying meanings. The process of interviews was used to fill up the 'gaps' from observation.

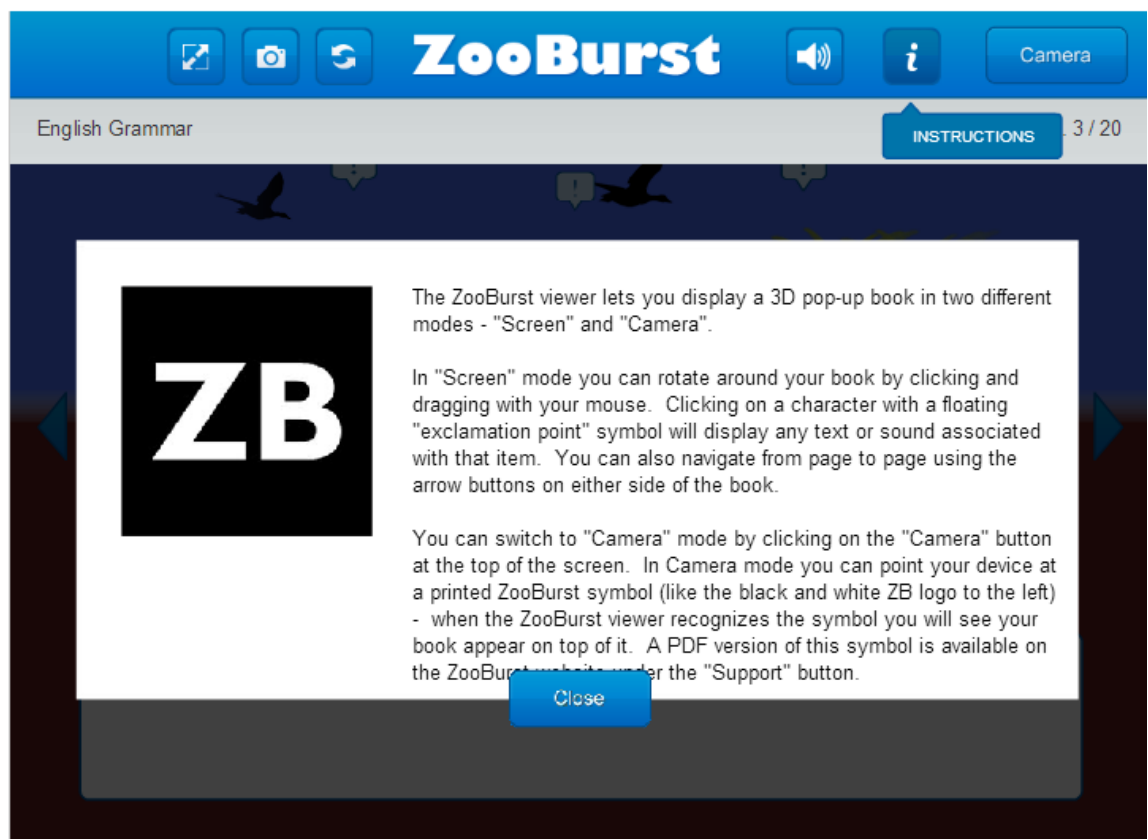

Figure 1 Motivational Design: Nine Step Model Adapted from Keller (2000)

\section{IV. $\quad$ AUGMENTED REALITY (AR) POP-UP BOOK}

There are many augmented reality (AR) educational application that are used to support learning. However, one of the missing components in the existing applications is motivation elements. Thus, this research study has adapted Keller's ARCS model of motivational design as shown in Figure 1 for the development of motivational AR pop-up book in English language learning which focuses on English grammar. This motivational design contains a systematic design process with nine-step. According to Keller, "they provide the basis for the second major feature of the ARCS model which is the systematic design process that assists you in creating motivational tactics that match student characteristics and need" [10].

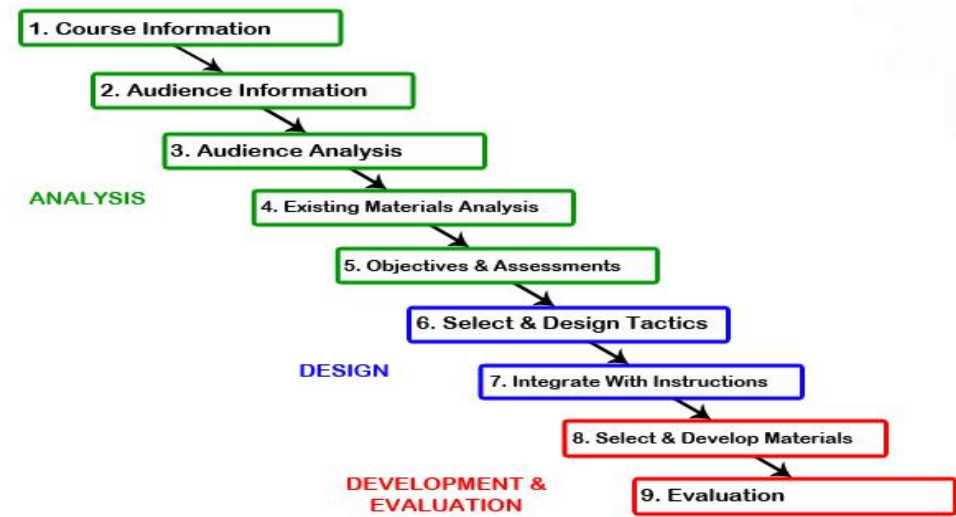

Figure 2 Instruction

Following are a few illustrations of the final augmented reality (AR) pop-up book that has been developed with ZooBurst. 


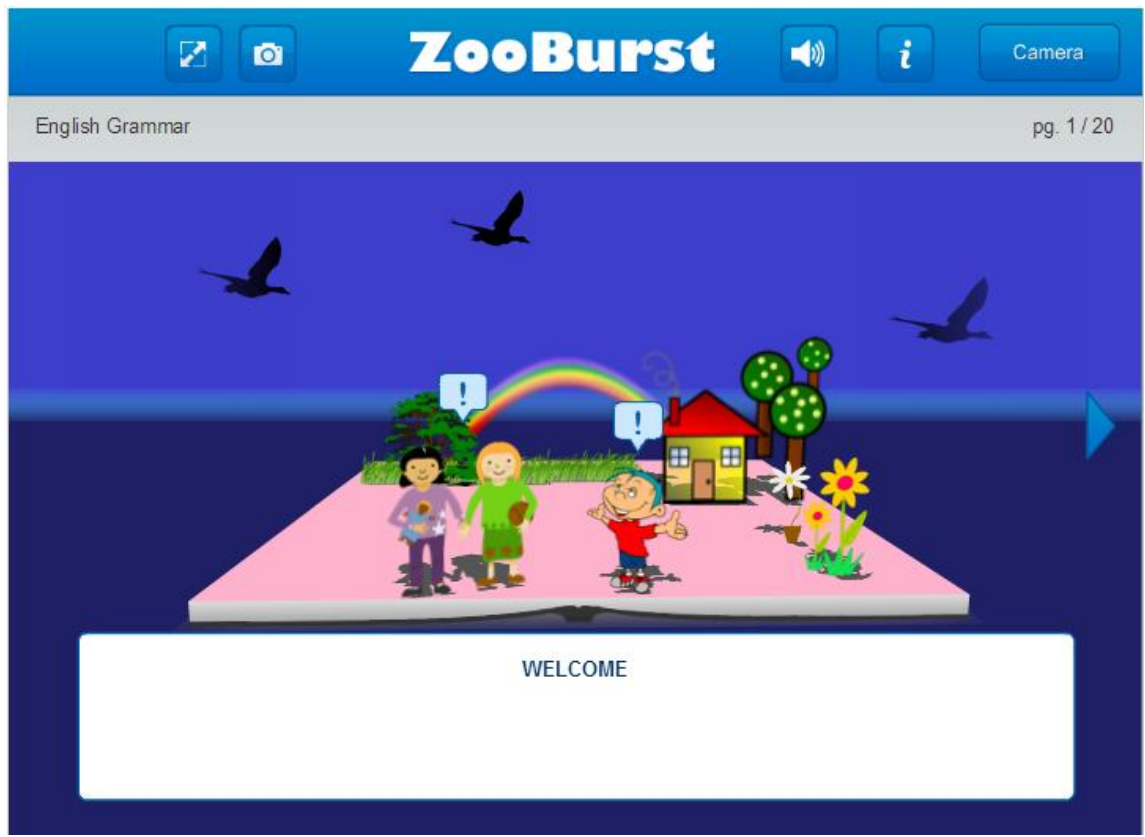

Figure 3 Welcome Page

Figure 3 represents the first page of the augmented reality (AR) pop-up book. The page is displayed with dynamic multimedia elements such as animation, graphics, texts, and sound. The 3D image is displayed through a camera mode. Then, to display AR mode, a printed code as shown in Figure 2 is held by students in front of the webcam. The perceptual, arousal, inquiry arousal, and variability are applied.

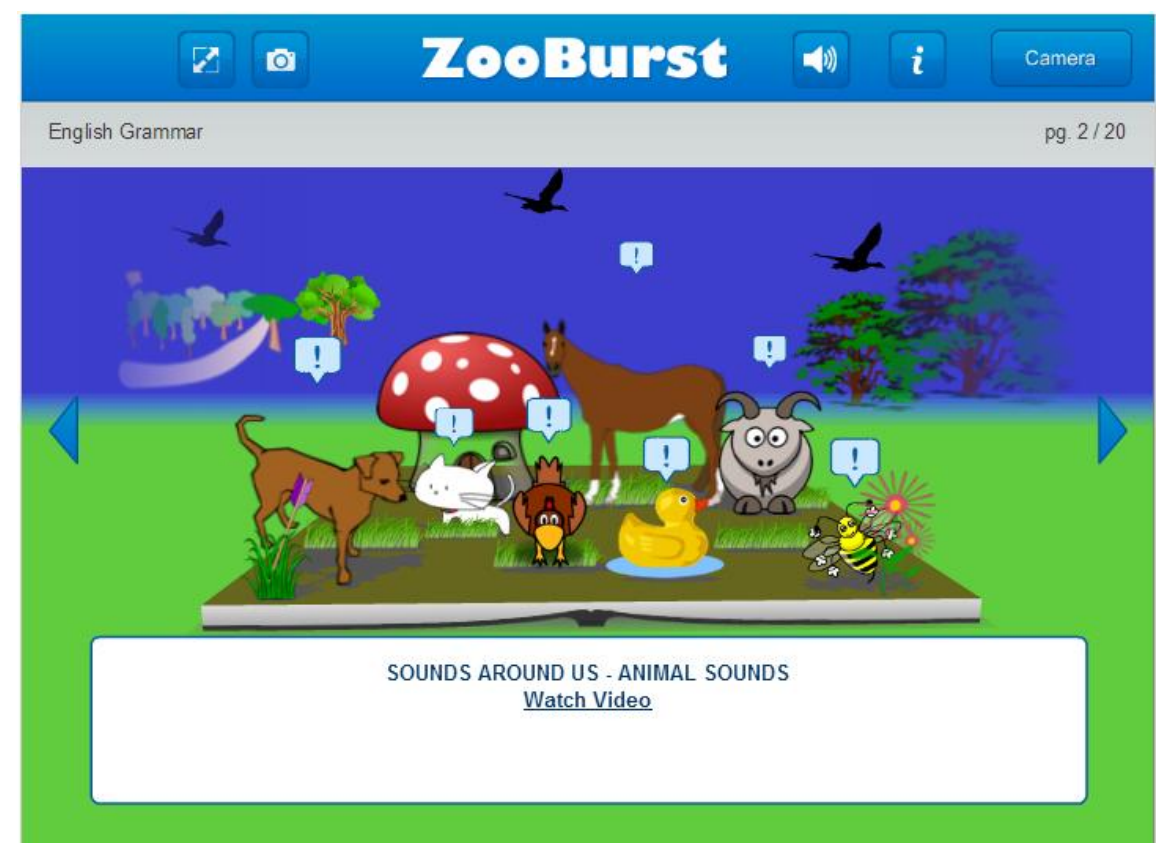

Figure 4 Animal Sounds

Figure 4 represents the second page of the augmented reality (AR) pop-up book. The page starts with the first topic of English grammar which is animal sounds. It is based on the primary school Year One English syllabus. The motive matching and familiarity are applied.

The rest of the pages represent more topics on English grammar. 


\section{FINDINGS}

This section reports the findings of the observation and semi-structured interview carried out on primary school students' motivation using augmented reality (AR) pop-up book in English language learning.

\section{A. Observation}

Descriptive statistics on mean was performed to describe the level of motivation on five participants. Apart from that, frequency diagrams and pie charts were used to show the distribution of the data. Finally, the significant value for reliability test is shown to measure internal consistency that is, how closely related a set of items are as a group.

Table 1: Descriptive Statistics: Minimum, Maximum, Mean, and Standard Deviation for Motivation in English Language Learning Using Augmented Reality (AR) Pop-Up Book

\begin{tabular}{lllllr}
\hline Description & N & Minimum & Maximum & Mean & Std. Deviation \\
\hline Attention Q1 & 5 & 3.00 & 3.00 & 3.0000 & 00000 \\
Attention Q2 & 5 & 2.00 & 3.00 & 2.6000 & .54772 \\
Attention Q3 & 5 & 2.00 & 3.00 & 2.6000 & .54772 \\
Attention Q4 & 5 & 1.00 & 3.00 & 2.2000 & 1.09545 \\
Attention Q5 & 5 & 3.00 & 3.00 & 3.0000 & .00000 \\
Attention Q6 & 5 & 1.00 & 1.00 & 1.0000 & .00000 \\
Relevance Q1 & 5 & 2.00 & 3.00 & 2.6000 & .54772 \\
Relevance Q2 & 5 & 1.00 & 3.00 & 2.4000 & .89443 \\
Relevance Q3 & 5 & 1.00 & 3.00 & 2.2000 & 1.09545 \\
Confidence Q1 & 5 & 3.00 & 3.00 & 3.0000 & .00000 \\
Confidence Q2 & 5 & 2.00 & 3.00 & 2.6000 & .54772 \\
Confidence Q3 & 5 & 1.00 & 1.00 & 1.0000 & .00000 \\
Confidence Q4 & 5 & 3.00 & 3.00 & 3.0000 & .00000 \\
Satisfaction Q1 & 5 & 1.00 & 3.00 & 2.4000 & .89443 \\
Satisfaction Q2 & 5 & 1.00 & 3.00 & 2.2000 & 1.09545 \\
Satisfaction Q3 & 5 & 1.00 & 3.00 & 2.4000 & .89443 \\
Satisfaction Q4 & 5 & 1.00 & 3.00 & 2.2000 & \\
\hline
\end{tabular}

Attention Q1 in Table 1 represents 'Shows initial interest in lesson' has a spread of 0.00 over 3.00 mean with the maximum score of 3.00 . The frequency diagram and pie chart showed the percentage of $100 \%$ scored on accomplished very.

Attention Q2 in Table 1 represents 'Interest retained during lesson' has a spread of 0.55 over 2.60 mean with the maximum score of 3.00 and minimum score of 2.00. The frequency diagram and pie chart showed two participants with the percentage of $40 \%$ scored on more emphasis and three participants with the percentage of $60 \%$ scored on accomplished very well.

Attention Q3 in Table 1 represents 'Shows curiosity for aspects of lesson' has a spread of 0.55 over 2.60 mean with the maximum score of 3.00 and minimum score of 2.00. The frequency diagram and pie chart showed two participants with the percentage of $40 \%$ scored on more emphasis and three participants with the percentage of $60 \%$ scored on accomplished very well.

Attention Q4 in Table 1 represents 'Retains attention throughout the lesson' has a spread of 1.09 over 2.20 mean with the maximum score of 3.00 and minimum score of 1.00 . The frequency diagram and pie chart 
showed two participants with the percentage of $40 \%$ scored on not observed and three participants with the percentage of $60 \%$ scored on accomplished very well.

Attention Q5 in Table 5.0 represents 'Repetition and practice leads to boredom' has a spread of 0.00 over 3.00 mean with the maximum score of 3.00. The frequency diagram and pie chart showed all five participants with the percentage of $100 \%$ scored on accomplished very well.

Attention Q6 in Table 5.0 represents 'Method of lesson too hard/challenging to maintain attention' has a spread of 0.00 over 1.00 mean with the minimum score of 1.00 . The frequency diagram and pie chart showed all five participants with the percentage of $100 \%$ scored on not observed.

Relevance Q1 in Table 1represents 'Can relate method/lesson to personal interests/experiences' has a spread of 0.55 over 2.60 mean with the maximum score of 3.00 and minimum score of 2.00 . The frequency diagram and pie chart showed two participants with the percentage of $40 \%$ scored on more emphasis and three participants with the percentage of $60 \%$ scored on accomplished very well.

Relevance Q2 in Table 1 represents 'Understands how the method/content relates to learning goals/targets' has a spread of 0.89 over 2.40 mean with the maximum score of 3.00 and minimum score of 1.00 . The frequency diagram and pie chart showed one participant with the percentage of $20 \%$ scored on not observed, one participant with the percentage of $20 \%$ scored on more emphasis, and three participants with the percentage of $60 \%$ scored on accomplished very well.

Relevance Q3 in Table 5.0 represents 'Sees the point/purpose of lesson for longer term personal goals' has a spread of 1.09 over 2.20 mean with the maximum score of 3.00 and minimum score of 1.00 . The frequency diagram and pie chart showed two participants with the percentage of $40 \%$ scored on not observed and three participants with the percentage of $60 \%$ scored on accomplished very well.

Confidence Q1 in Table 5.0 represents 'Shows confidence about using the method' has a spread of 0.00 over 3.00 mean with the maximum score of 3.00. The frequency diagram and pie chart showed all five participants with the percentage of $100 \%$ scored on accomplished very well.

Confidence Q2 in Table 5.0 represents 'Believes that she/he can cope with the method' has a spread of 0.55 over 2.60 mean with the maximum score of 3.00 and minimum score of 2.00 . The frequency diagram and pie chart showed two participants with the percentage of $40 \%$ scored on more emphasis and three participants with the percentage of $60 \%$ scored on accomplished very well.

Confidence Q3 in Table 5.0 represents 'Communicates about difficulties/challenges of learning method' has a spread of 0.00 over 1.00 mean with the minimum score of 1.00 . The frequency diagram and pie chart showed all five participants with the percentage of $100 \%$ scored on not observed.

Confidence Q4 in Table 5.0 represents 'Takes control of lesson activities' has a spread of 0.00 over 3.00 mean with the maximum score of 3.00. The frequency diagram and pie chart showed all five participants with the percentage of $100 \%$ scored on accomplished very well.

Satisfaction Q1 in Table 5.0 represents 'Enjoy learning so much that wants to do more' has a spread of 0.89 over 2.40 mean with the maximum score of 3.00 and minimum score of 1.00 . The frequency diagram and pie chart showed one participant with the percentage of $20 \%$ scored on not observed, one participant with the percentage of $20 \%$ scored on more emphasis, and three participants with the percentage of $60 \%$ scored on accomplished very well.

Satisfaction Q2 in Table 5.0 represents 'Shows that working at lesson is worthwhile' has a spread of 1.09 over 2.20 mean with the maximum score of 3.00 and minimum score of 1.00 . The frequency diagram and pie chart showed two participants with the percentage of $40 \%$ scored on not observed and three participants with the percentage of $60 \%$ scored on accomplished very well.

Satisfaction Q3 in Table 5.0 represents 'Shows pleasure during the lesson' has a spread of 0.89 over 2.40 mean with the maximum score of 3.00 and minimum score of 1.00 . The frequency diagram and pie chart showed one participant with the percentage of $20 \%$ scored on not observed, one participant with the percentage of $20 \%$ scored on more emphasis, and three participants with the percentage of $60 \%$ scored on accomplished very well.

Satisfaction Q4 in Table 5.0 represents 'Experiences satisfaction when lesson completed' has a spread of 1.09 over 2.20 mean with the maximum score of 3.00 and minimum score of 1.00 . The frequency diagram and pie chart showed two participants with the percentage of $40 \%$ scored on not observed and three participants with the percentage of $60 \%$ scored on accomplished very well. 


Cronbach's Alpha $\quad$ Cronbach's Alpha Based on Standardized Items $\quad$ N of Items

The reliability test was done using on the observation checklist using Statistical Package for Social Science (SPSS) and the alpha coefficient for the 12 items was 0.990, suggesting that the items have relatively high internal consistency.

\section{B. Semi-structured Interview}

The semi-structured interview had been carried out to confirm the results derived from the observation. The questions were asked according to the ARCS model of motivation. The interview had been done in Malay language and the answers given from the participants were recorded accurately, without modification.

\section{Attention}

Perceptual arousal as a whole was found to be interesting and captured their interest during learning.

Participants reviewed that the augmented reality (AR) pop-up book generated inquiry and they managed to solve those problems by themselves after a few tries.

Finally, for variability, there were two participants who were lack of interest in English language learning and using computer for some reasons, thus they did not give full attention during the learning process. They, however, still had the interest to learn in a way that it did not put aside the school books.

\section{Relevance}

Participants were able to apply the knowledge in the classroom setting, and able to enhance their skill in computing. However, participant 4, and participant 5 replied in a tone that indicated them having low literacy in English language learning.

English was always coincides with their own desires. Thus, the learning was more relevance as it matches their motive and value in learning. While, having low literacy in English language learning has made participant 5 felt a coercive learning.

Familiarity as a whole according to all participants was the learning experiences in English language learning and computing related to the AR pop-up book.

\section{Confidence} session.

Participants reviewed that the augmented reality (AR) pop-up book assisted them in the learning

Participants 1, 2, and 3 described that they were able to remember the lesson while participant 4 and 5 slightly remember what they have learned. However, all the participants felt that the content was enough for them to learn.

Participants described that they went through all the topics as they had more control over their time for the learning. They felt more confident in achieving success through the personal control during the lesson.

\section{Satisfaction}

Participants were given an opportunity to speak English after the learning session and they were able to use their newly acquired knowledge to have the intrinsic reinforcement through the short story telling session. However, participant 4 and 5 did experienced emotional distress at the beginning as they had low literacy in English but they managed to give it a try.

Participants were all excited to have the rewards and it gives them satisfaction in learning, thus increase their intention to learn more especially for participant 4 and 5.

Equity as a whole was found to be easy for the participants in terms the ease of use for the learning material and the content itself which was cleared and easy to learn.

\section{Discussion}

All five students were observed to show initial interest in lesson, interest retained during lesson, shows curiosity for aspects of lesson, and retains attention throughout the lesson in the learning session. This can be further described from the interview process where students were excited about computer aided learning hence, attracted to the augmented reality pop-up elements. This can be shown in their happy facial expression. This phenomenon can be supported by Sali, [12]. In the research, she stated that "various studies have indicated that 
variability, unexpected events, curiosity and incompatible situations stimulate attention". However, two students were observed to have lack of attention because they had low literacy in English language.

Next, three students were successful observed can relate method/lesson to personal interest/experiences, understand how the method/content relates to learning goals/targets, and see the point/purpose of lesson for longer term personal goals. This can be further described from the interview process where students were able to apply their knowledge in the classroom setting. Also, the learning session matched their motive and value. The augmented reality (AR) pop-up book was designed in a way that familiar to their learning experiences. This can be supported by Keller, [10] where he stated that, although a curiosity is aroused, motivation is lost if the content has no perceive value to the learners. Two students were observed that the lesson was not fully relevance to them with the same reason of having low literacy in English language. This can be described from the interview process where one of the two students felt a coercive learning for having low literacy.

All students were observed to shows confidence about using the method, believe that she/he can cope with the method, and takes control of lesson activities. This can be further described from the interview process where students were able to build success as their learning requirement was fulfilled by the learning material. They were also believes to achieve success for having more control over their time for the learning session. This can be supported by Keller, [10] that confidence is not likely to increase if the students believe that success was due to external factor such as luck or lack of challenge.

Finally, the observation was on satisfaction as the result of the learning session. Three students were successfully observed to enjoy learning so much that wants to do more, shows that working at lesson is worthwhile, shows pleasure during the lesson, and experiences satisfaction when lesson completed. Two students were not observed on most criteria for the satisfaction. However, this can be further described from the interview process where all students were actually showing their satisfaction by using their newly acquired knowledge to have the intrinsic reinforcement through a short story telling session although at the beginning the two students with low literacy experienced emotional distress but they managed to give it a try. Besides that, students were all excited to have rewards as the feeling of satisfaction with their learning session. In addition, Sali, [12] reported that motivation in high degree is realized as a result of satisfaction. The interview session reviewed that students were satisfied with the difficulty level of the learning material. Also, this phenomenon can be supported by Keller, [11] where he stated that it is important for students to feel the amount of work required by the course was appropriate.

\section{Conclusions}

The observation and semi-structured interview successfully answered both research questions. Year One students perceive augmented reality (AR) pop-up book as being motivational through the attention, relevance, confidence, and finally the feeling of satisfaction as a result from the learning session. Besides that, the important elements that contributed to the success in English language learning by using augmented reality (AR) pop-up book were perceptual arousal, inquiry arousal, variability, goal orientation, motive matching, familiarity, learning requirements, success opportunities, personal control, intrinsic reinforcement, extrinsic rewards, and equity. All these elements are essential for students to be fully motivated in learning.

Apart from that, through the continuing research in augmented reality (AR) technologies and motivation, classroom can be even more immersive and inspiring for students, thus enhance their performance.

\section{References}

[1] Musa, N.C., Lie, K.Y., \& Azman, H. (2012). Exploring English Language Learning and Teaching in Malaysia. GEMA Online Journal of Language Studies, 12(1), 35-51.

[2] Legault, L., Green-Demers, I., \& Pelletier, L. (2006).Why Do High School Students Lack Of Motivation In Classroom? Toward an Understanding of Academic Amotivation and The Role Of Social Support. Journal of Educational Psychology, 98(3), 567582 .

[3] Wei, L.S.,\& Habibah Elias (2011). Relationship Between Students' Perception of Classroom Environment and Their Motivation in Learning English Language. GEMA Online Journal of Language Studies, 1(21), 240-250.

[4] Yuen, S., Yaoyuneyong, G., \& Johnson, E. (2011). Augmented Reality: An Overview and Five Directions for AR in Education.sicetorg,4,119-140.Retrieved from

http://search.ebscohost.com/login.aspx?direct=true\&db=bwh\&AN=201201101315PR.NEWS.USPR.MM32350

[5] Liarokapis, F., \& Anderson, E. F. (2010). Using Augmented Reality as a Medium to Assist Teaching in Higher Education. Most, 9-16. Education Program, Eurographics Association. Retrieved from http://nestor.coventry.ac.uk/ eikea/docs/eg_eduAR.pdf

[6] Song, S. H., \& Keller, J. M. (2001). Effectiveness of motivationally adaptive computer-assisted instruction on the dynamic aspects of motivation. Educational Technology Research \& Development, 49(2), 5-22. doi:10.1007/BF02504925

[7] Kerawalla, L., Luckin, R., Seljeflot, S., \& Woolard, A. (2006). Making it real: exploring the potential of Augmented Reality for teaching primary school science. Virtual Reality, 10(3-4), 163-174. Springer. Retrieved from http://dx.doi.org/10.1007/s10055006-0036-4

[8] Lee, S. H., Choi, J., \& Park, J.-il. (2009). Interactive e-learning system using pattern recognition and augmented reality. IEEE Transactions on Consumer Electronics (Vol. 55, pp. 883-890). IEEE. doi:10.1109/TCE.2009.5174470 
[9] Zubairi, A.M., \& Sarudin, I. (2009). Motivation to Learn a Foreign Language in Malaysia. GEMA Online Journal of Language Studies, 9(2), 73-87.

[10] Keller, J. M. (2000). How to integrate learner motivation planning into lesson planning: The ARCS model approach. Paper presented at VII Semanario, Santiago, Cuba.

[11] Keller, J. M. (2008). First principles of motivation to learn and e3-learning. Distance Education, 29(2), 175-185. doi:10.1080/01587910802154970

[12] Sali, J.B. (2008). Designing Motivational Learning Systems in Distance Education. Turkish Online Journal of Doistance EducationTOJDE, 9(3), 149-161. Retrieved from https://tojde.anadolu.edu.tr/tojde31/pdf/article_13.pdf

[13] Barab, S., \& Squire, K. (2004). Design-Based Research: Putting a Stake in the Ground. (S. Barab \& K. Squire, Eds.)The Journal of the Learning Sciences, 13(1), 1- 14. doi:10.1207/s15327809j1s1301_1

[14] McGriff, S.J. (1999). SUMMARY PAPER: Motivational Systems. Chapter 19-Handbook of Human Performance Technology. Instructional Systems 551-Human Performance Technology. Retrieved from http://slo.sbcc.edu/wp- content/uploads/motivation.pdf

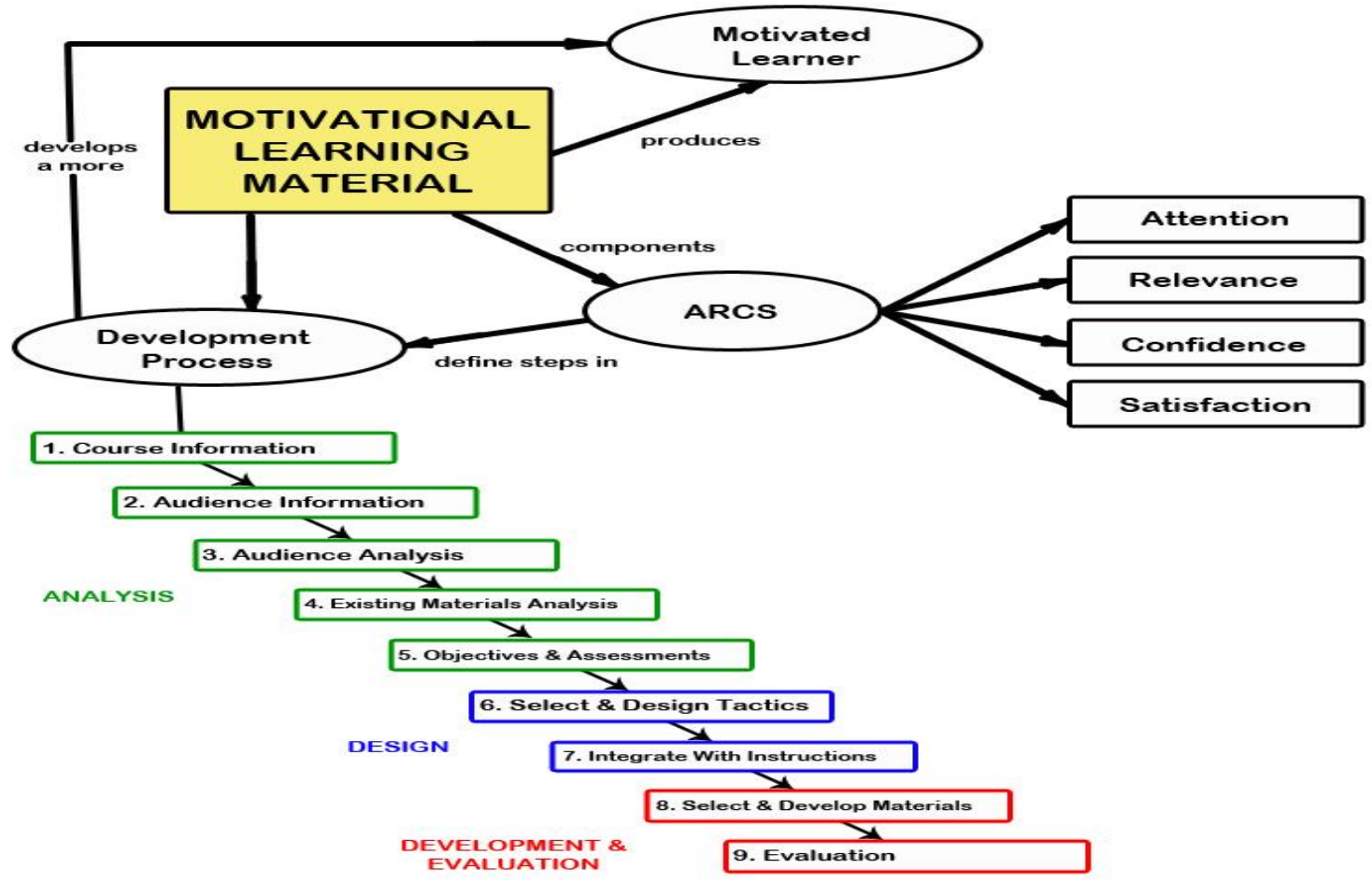

Appendix 1: Research Framework Adapted from Steven J. McGriff (1999)

Appendix 2: Framework of motivational augmented reality (AR) pop-up book in English language learning (2.0)

Framework of motivational augmented reality (AR) pop-up book in English language learning (2.0) Motivation (2.4)

\begin{tabular}{|c|c|c|c|}
\hline $\begin{array}{l}\text { Attention } \\
2.4 .1\end{array}$ & $\begin{array}{l}\text { Relevance } \\
2.4 .2\end{array}$ & $\begin{array}{l}\text { Confidence } \\
2.4 .3\end{array}$ & $\begin{array}{l}\text { Satisfaction } \\
2.4 .4\end{array}$ \\
\hline $\begin{array}{l}\text { Arousing and sustaining } \\
\text { curiosity and interest }\end{array}$ & $\begin{array}{l}\text { Learner needs, interest, and } \\
\text { motives. }\end{array}$ & Develop positive expectations. & $\begin{array}{l}\text { Extrinsic and intrinsic } \\
\text { reinforcement for effort. }\end{array}$ \\
\hline $\begin{array}{l}\text { A. Perceptual Arousal } \\
2.4 .1 .1\end{array}$ & $\begin{array}{l}\text { A. Goal Orientation } \\
2.4 .2 .1\end{array}$ & $\begin{array}{l}\text { A. Learning Requirements } \\
2.4 .3 .1\end{array}$ & $\begin{array}{l}\text { A. Intrinsic Reinforcement } \\
2.4 .4 .1\end{array}$ \\
\hline $\begin{array}{l}\text { Capture interest using novel } \\
\text { approaches; inject personal or } \\
\text { emotional material. }\end{array}$ & $\begin{array}{l}\text { Develop goals or demonstrate } \\
\text { utility of instruction to meet the } \\
\text { needs. }\end{array}$ & $\begin{array}{l}\text { Assist in building a positive } \\
\text { expectation for success. }\end{array}$ & $\begin{array}{l}\text { Meaningful opportunities for } \\
\text { learners to use their newly } \\
\text { acquired knowledge. }\end{array}$ \\
\hline $\begin{array}{l}\text { B. Inquiry Arousal } \\
2.4 .1 .2\end{array}$ & $\begin{array}{l}\text { B. Motive Matching } \\
2.4 .2 .2\end{array}$ & $\begin{array}{l}\text { B. Success Opportunities } \\
2.4 .3 .2\end{array}$ & $\begin{array}{l}\text { B. Extrinsic Rewards } \\
2.4 .4 .2\end{array}$ \\
\hline $\begin{array}{l}\text { Stimulate an attitude of inquiry } \\
\text { by using mystery, unresolved } \\
\text { problems, and other techniques. }\end{array}$ & $\begin{array}{l}\text { Provide appropriate choices, } \\
\text { responsibilities, and influence } \\
\text { using authentic exercises; match } \\
\text { individual to learning style. }\end{array}$ & $\begin{array}{l}\text { Learning experiences that } \\
\text { support learner's beliefs in their } \\
\text { competence. }\end{array}$ & $\begin{array}{l}\text { Reinforcement to the learner's } \\
\text { success. }\end{array}$ \\
\hline
\end{tabular}


The Use of Augmented Reality Pop-Up Book To Increase Motivation in English Language Learning

\begin{tabular}{|l|l|l|l|}
\hline & & & \\
\hline $\begin{array}{l}\text { C. Variability } \\
\text { 2.4.1.3 }\end{array}$ & $\begin{array}{l}\text { C. Familiarity } \\
2.4 .2 .3\end{array}$ & $\begin{array}{l}\text { C. Personal Control } \\
2.4 .3 .3\end{array}$ & $\begin{array}{l}\text { C. Equity } \\
2.4 .4 .3\end{array}$ \\
$\begin{array}{l}\text { Maintain interest using } \\
\text { variations in presentation style. }\end{array}$ & $\begin{array}{l}\text { Tie instruction to learner's } \\
\text { experience using concrete } \\
\text { example and analogies to relate } \\
\text { materials to learner's live. }\end{array}$ & $\begin{array}{l}\text { Techniques that allow learners } \\
\text { to clearly know their success is } \\
\text { abilities. }\end{array}$ & $\begin{array}{l}\text { Assist learners in anchoring a } \\
\text { positive feeling about their } \\
\text { accomplishments. }\end{array}$ \\
\hline
\end{tabular}

Note: Numbers refer to sub-heading within Chapter two

\section{Appendix 3: Observation checklist}

\section{OBSERVATION CHECKLIST}

Name:

Date:

Time:

Respond to each statement using the following scale:

Not observed

Content Organization

\section{ATTENTION}

Shows initial interest in lesson

Interest retained during lesson

Shows curiosity for aspects of lesson

Retains attention throughout the lesson

Repetition and practice leads to boredom

Method of lesson too hard /challenging to maintain attention

\section{RELEVANCE}

Can relate method / lesson to personal interests/ experiences

Understands how the method / content relates to learning goals / targets

Sees the point / purpose of lesson for longer term personal goals

\section{CONFIDENCE}

Shows confidence about using the method

Believes that she/he can cope with the method 
Communicates about difficulties /

challenges of learning method

Takes control of lesson activities

\section{SATISFACTION}

Enjoyed learning so much that wants to do more

Shows that working at lesson is worthwhile

Shows pleasure during the lesson

Experiences satisfaction when lesson completed

\section{Appendix 4: Semi-structured interview questions}

\section{Interview Protocol}

The following information is to be used by the researcher before, during, and after the interview.

The researcher follows these steps:

\section{Before the interview}

- Schedule interview with student during recess time. Be sure to schedule the room for the interview to take place with a teacher present.

- Request permission ahead of time to record the interview.

- Assure the teacher and headmaster that results will be kept confidential.

- Have all materials organized and ready for the interview.

- Make sure to test recording equipment.

- Make sure to bring extra batteries for recording equipment and use a high quality tape.

During the interview

- Before beginning the interview session, the researcher introduces herself and records students' name, date, and time.

- Ask questions as written, but if the participant seems to misinterpret the question or to get "off track" with his/her response, asks probing questions to clarify his/her response.

- $\quad$ Try to avoid a dialogue during the interview-lets the participant do the talking.

- In conclusion, asks the participant if he/she have any questions or comments.

After the interview

- Write up (verbally attach) a brief report as soon as possible after the interview. Make sure to clarify any unusual occurrences (such as an interruption in the interview), or her impressions of strange response from the participant. (e.g.,Were there any questions that he/she seemed to find offensive or threatening, or questions that seemed unusually difficult to answer?)

- Describe any insights that may not have registered through audio medium, or any other unusual occurrences during meeting.

\section{Interview Questions}

Name:

Date:

Time:

Introduce yourself and the purpose of the interview:

After I introduce myself and have the recorder started, I will read the following:

"Hi, thank you for learning with me today! What should I call you? Now I would like to ask a few questions to you on what you have learned just now. You won't get any marks for answering my questions. I will take 10 minutes. Do you have any questions to ask me before we start?"

Confidentially:

"Not to worry because I will keep all your answers as a secret"

"You are free to answer anything that you want and don't be scared"

\section{ATTENTION}

\section{Perceptual Arousal}


Q1: Did you enjoy the lesson?

Q2: What did you like most about the lesson?

2. Inquiry Arousal

Q1: What problems did you have just now?

Q2: So, what have you done?

3. Variability

Q1: What were the things that make you like to use when learning?

Q2: What about the things that you like to see and hear?

\section{RELEVANCE}

4. Goal Orientation

Q1: What can you do with your learning today?

\section{Motive Matching}

Q1: You are learning English because you yourself want to learn or other people ask you to learn?

6. Familiarity

Q1: Do you know how to use a computer? If yes, for what?

Q2: Have you learned about the topics before this?

\section{CONFIDENCE}

7. Learning Requirements

Q1: Did you need help in your lesson from beginning until you finish just now? Why?

8. Success Opportunities

Q1: Can you remember the lesson?

Q2: Did you feel the topics enough for you, or a lot?

9. Personal Control

Q1: Did you complete all the topics in the lesson?

\section{SATISFACTION}

10. Intrinsic Reinforcement

Q1: Well, I want to give you a chance to tell me about yourself, your favorite colors, your family, and anything that you like to say right now. Make sure it is in English. Let us start.

\section{Extrinsic Rewards}

Q1: Do you like to have something since you have finished your lesson with me? Why? Why not?

12. Equity

Q1: Was the lesson easy or difficult to learn? 